\title{
$\beta$-Enaminonitriles in heterocylic synthesis: Synthesis of new tetrahydropyridinethione, pyridopyrimidines, pyridotriazines and dihydropyridines
}

\author{
IBRAHIM SAAD ABDEL HAFIZ ${ }^{1, *}$, MAHMOUD MOHAMED MAHFOUZ RAMIZ ${ }^{2}$, \\ FIVIAN FAROK MAHMOUD ${ }^{3}$ and ELHAM SAYED DARWISH ${ }^{4}$ \\ ${ }^{1}$ Department of Chemistry, Faculty of Education, Suez Canal University, Arish, Egypt \\ ${ }^{2}$ Faculty of Electronic Engineering, Menofia University, Menouf, Egypt \\ ${ }^{3}$ Department of Chemistry, Faculty of Science, Al-Azhar University, Cairo, Egypt \\ ${ }^{4}$ Department of Chemistry, Faculty of Science, Cairo University, Cairo, Egypt \\ e-mail: dr_ibrahim_saad@maktoob.com
}

MS received 10 November 2007; revised 6 March 2008

\begin{abstract}
The chemistry of enaminonitrile and enaminone derivatives has been explored for the synthesis of heterocyclic compounds. A tetrahydropyridinthione was prepared from the reaction of 2aminocrotononitrile with cyanothioacetamide. This compound reacted with electrophilic reagents and isothiocyanates to yield a number of heterocyclic compounds.
\end{abstract}

Keywords. $\beta$-Enaminonitriles; tetrahydropyridinethione; pyridopyrimidines; pyridotriazines; dihydropyridines.

\section{Introduction}

$\beta$-Aminoalkenonitrile has proven to be valuable reagents in the synthesis of a wide variety of unique heterocyclic systems such as pharmaceuticals, fungicides and solvatochromatic dyes. Recently, a number of papers and patents concerning the importance of $\beta$-enaminonitriles in the synthesis of biologically active compounds, dihydropyridines analogous to nifedipine and amlodipine as potential calcium channel blockers in the treatment of angina and hypertension have been found.

\section{Experimental}

All melting points are uncorrected. IR spectra were recorded (KBr) with a Shimadzu FTIR-8201 PC spectrophotometer. The ${ }^{1} \mathrm{H}$ NMR spectra were recorded on a Varian Germini $200 \mathrm{MHz}$ spectrometer in dimethyl sulphoxide- $d_{6}$ as a solvent and TMS as an internal reference. Mass spectra were performed on a Shimadzu GCMS-OP 1000 Ex instrument using the direct inlet system and El + QI MSLMRUPLR.

\footnotetext{
*For correspondence
}

Microanalyses were performed by the microanalytical center at Cairo University.

\subsection{4,6-Diamino-1,2,3,4-tetrahydro-4-methyl-2- thioxopyridine-3-carbonitrile(4)}

A mixture 2-aminocrotononitrile (1) $(0.82 \mathrm{~g}, 0.01 \mathrm{~mol})$ in dioxane $(20 \mathrm{ml})$ and cyanothioacetamide $(1 \mathrm{~g}$, $0.01 \mathrm{~mol}$ ) was refluxed for $4 \mathrm{~h}$. The solid product, so formed, was collected by filtration and crystallized from dimethylforamide as yellow crystals; m.p. $>300^{\circ} \mathrm{C}$; yield $(90 \%)$; IR $(\mathrm{KBr})$ : v $3300\left(\mathrm{NH}_{2}\right)$, $3210(\mathrm{NH}), 2220(\mathrm{CN}), 1640(\mathrm{CS}) \mathrm{cm}^{-1}$; MS: $\mathrm{m} / z$ (\%), 182 (34), 165 (100), 95 (25); ${ }^{1} \mathrm{H}$ NMR: $\delta 2 \cdot 20$ $\left(s, 3 \mathrm{H}, \mathrm{CH}_{3}\right), 3 \cdot 10(s, 1 \mathrm{H}, \mathrm{CH}), 5 \cdot 92(s, 1 \mathrm{H}$, olefinic$\mathrm{H}), 7 \cdot 24-7 \cdot 30\left(b r, 5 \mathrm{H}, 2 \mathrm{NH}_{2}\right.$ and $\left.\mathrm{NH}\right)$.

Anal. calcd. For $\mathrm{C}_{7} \mathrm{H}_{10} \mathrm{~N}_{4} \mathrm{~S}: \mathrm{C} 46 \cdot 1 ; \mathrm{H} 5 \cdot 5 ; \mathrm{N}$ $30 \cdot 7$; S $17 \cdot 6 \%$.

Found: C 46.3; H 5.8; N 31.07; S 17.8\%.

\subsection{2-Amino-4-mehyl-5-cyanopyridine-6-thiol (5)}

A suspension of tetrahydro-pyridinethione 4 (1.8 g, $0.01 \mathrm{~mol})$ in acetic acid $(20 \mathrm{ml})$ was refluxed for $3 \mathrm{~h}$. The solid product, so formed, was collected by 
filtration and crystallized from dioxane as yellow crystals; mp $220-222^{\circ} \mathrm{C}$; yield (64\%); IR (KBr): v $3310\left(\mathrm{NH}_{2}\right), 2215(\mathrm{CN}) \mathrm{cm}^{-1}$; MS: $m / z(\%), 165$ (65), 121 (50), $105(100) ;{ }^{1} \mathrm{H}$ NMR: $\delta 3.05(s, 1 \mathrm{H}$, $\mathrm{SH}), 3.20\left(s, 3 \mathrm{H}, \mathrm{CH}_{3}\right), 4.60\left(s, 2 \mathrm{H}, \mathrm{NH}_{2}\right), 6 \cdot 70(s$, $1 \mathrm{H}$, aromatic-H).

Anal. calcd. For $\mathrm{C}_{7} \mathrm{H}_{7} \mathrm{~N}_{3} \mathrm{~S}$ : C 50.9; H 4.3; N 25.4; S $19.4 \%$.

Found: C 50.6; H 4.1; N 25.1; S 19.2\%.

\subsection{General procedures for the preparation of pyridopyrimidinethione $(\mathbf{9 a}, \boldsymbol{b})$}

To a solution of tetrahydro-pyridinethione $4(1.8 \mathrm{~g}$, $0.01 \mathrm{~mol})$ in ethanol $(20 \mathrm{ml})$ ethoxyethylenemalononitrile derivatives $6 \mathbf{a}$ or $6 \mathbf{b}(0.01 \mathrm{~mol})$ and a catalytic amount of piperidine were added. The reaction mixture was refluxed for $3 \mathrm{~h}$ and was left to cool. The solid product, so formed was collected by filtration and crystallized from the proper solvent to give $\mathbf{9 a}, \mathbf{b}$

$2.3 a \quad 2,8$-Diamino-8-methyl-6-thioxo-7,8-dihydro6H-pyrido[1,2-a]pyrimidine-3,7-dicarbonitrile (9a): Compound 9a was obtained as yellow crystals (dioxane), m.p. $225-227^{\circ} \mathrm{C}$; yield $(70 \%)$; IR ( $\left.\mathrm{KBr}\right): v$ $3415\left(\mathrm{NH}_{2}\right), 2205(\mathrm{CN}), 1640(\mathrm{CS}) \mathrm{cm}^{-1} ;{ }^{1} \mathrm{H}$ NMR: $\delta 2.30\left(s, 3 \mathrm{H}, \mathrm{CH}_{3}\right), 3 \cdot 10(s, 1 \mathrm{H}, \mathrm{CH}), 6.00(s, 1 \mathrm{H}$, olefinic-H), 7.30-7.42 (m, 5H, olefinic-H and 2NH $\mathrm{NH}_{2}$; MS: $m / z$ (\%), 258 (19), 179 (28), 165 (100).

Anal. calcd. For $\mathrm{C}_{11} \mathrm{H}_{10} \mathrm{~N}_{6} \mathrm{~S}: \mathrm{C}$ 51.2; $\mathrm{H} 4.9 ; \mathrm{N}$ $32 \cdot 5$; S $12 \cdot 4 \%$.

Found: C 51.0; H 3.7; N 32.2; S 12.1\%.

$2.3 \mathrm{~b}$ Ethyl 2,8-diamino-7-cyano-7,8-dihydro-8methyl-6-thioxo-6H-pyrido[1,2-a] pyrimidine-3carboxlate (9b): Compound 9b was obtained as orange crystals (dioxane), m.p. $250-252^{\circ} \mathrm{C}$; yield (74\%); IR (KBr): v $3415\left(\mathrm{NH}_{2}\right), 2205(\mathrm{CN}), 1640$ (CS) $\mathrm{cm}^{-1} ;{ }^{1} \mathrm{H}$ NMR: $\delta 2 \cdot 30\left(s, 3 \mathrm{H}, \mathrm{CH}_{3}\right), 3 \cdot 10(s$, $1 \mathrm{H}, \mathrm{CH}), 6.00(\mathrm{~s}, 1 \mathrm{H}$, olefinic-H), 7.30-7.42 (m, 5H, olefinic-H and $\left.2 \mathrm{NH}_{2}\right)$; MS: $m / z(\%), 258$ (19), 179 (28), 165 (100)

Anal. calcd. For $\mathrm{C}_{13} \mathrm{H}_{15} \mathrm{~N}_{5} \mathrm{SO}_{2}$ : C 51.1; H 5.0; N 22.9; S $10.5 \%$.

Found: C $50 \cdot 8 \cdot 0 ; \mathrm{H} 5 \cdot 3 ; \mathrm{N} 22 \cdot 6 ; \mathrm{S} 10 \cdot 3 \%$.

$2.3 \mathrm{c}$ General procedures for the preparation of pyridopyrimidinethione $(13 a-f)$ : To a solution of tetra-hydropyridinethione $4(1.8 \mathrm{~g}, 0.01 \mathrm{~mol})$ in ethanol $(20 \mathrm{ml})$ arylidine-malononitrile or arylidine- cyanothioacetamide derivatives $8 \mathbf{a}-\mathbf{f}(0.01 \mathrm{~mol})$ and a catalytic amount of piperidine were added. The reaction mixture was refluxed for $4 \mathrm{~h}$ and then was left to cool. The solid product so, formed was collected by filtration and crystallized from the proper solvent to give 13a-f.

2.3d 2,8-diamino-8-methyl-4-phenyl-6-thioxo-7,8dihydro-6H-pyrido[1,2-a] pyrimidine-3,7-dicarbonitrile (13a): Compound 13a was obtained as yellow crystals (dioxane), m.p. $231-233^{\circ} \mathrm{C}$; yield $(60 \%)$; IR (KBr): $v 3390\left(\mathrm{NH}_{2}\right), 2200(\mathrm{CN}), 1645(\mathrm{CS}) \mathrm{cm}^{-1} ;{ }^{1} \mathrm{H}$ NMR: $\delta 1.35\left(s, 3 \mathrm{H}, \mathrm{CH}_{3}\right), 3 \cdot 10(s, 1 \mathrm{H}, \mathrm{CH}), 6.00(s$, $1 \mathrm{H}$, olefinic-H), 7.15-7.91 ( $\mathrm{m}, 9 \mathrm{H}$, aromatic-H and 2NH $\mathrm{NH}_{2}$; MS: $m / z$ (\%), 334 (24), 317 (39), 165 (100).

Anal. calcd. For $\mathrm{C}_{17} \mathrm{H}_{14} \mathrm{~N}_{6} \mathrm{~S}$ : C $61.6 ; \mathrm{H} 4.2 ; \mathrm{N}$ $25 \cdot 1 ; \mathrm{S} 9.6 \%$.

Found: C 50.8; H 5.3; N 22.6; S 10.3\%.

2.3e 2,8-diamino-8-methyl-6-thioxo-4-(4-chlorophenyl)-7,8-dihydro-1Hpyrido[1,2-a] pyrimidine3,7-dicarbonitrile (13b): Compound 13b was obtained as yellow crystals (dioxane/ehanol), m.p. $280-282^{\circ} \mathrm{C}$; yield $(60 \%)$; IR $(\mathrm{KBr}): v 3390\left(\mathrm{NH}_{2}\right)$, $2200(\mathrm{CN}), 1645(\mathrm{CS}) \mathrm{cm}^{-1}$; ${ }^{1} \mathrm{H}$ NMR: $\delta 1.35(s, 3 \mathrm{H}$, $\left.\mathrm{CH}_{3}\right), 3 \cdot 10(s, 1 \mathrm{H}, \mathrm{CH}), 6.00(s, 1 \mathrm{H}$, olefinic- $\mathrm{H})$, $7 \cdot 15-7.91\left(m, 9 \mathrm{H}\right.$, aromatic-H and $\left.2 \mathrm{NH}_{2}\right) ; \mathrm{MS}: \mathrm{m} / \mathrm{z}$ (\%), 334 (24), 317 (39), 165 (100).

Anal. calcd. For $\mathrm{C}_{17} \mathrm{H}_{13} \mathrm{~N}_{6} \mathrm{SCl}$ : C 55.4; H 3.6; N 22.8; S 8.7; $\mathrm{Cl} 9.6 \%$.

Found: C 55.7; H 3.9; N 22.6; S 8.4; C1 9.4\%.

$2.3 \mathrm{f}$ 2,8-diamino-8-methyl-6-thioxo-4-p-tolyl-7,8-dihydro-1H-pyrido [1,2-a] pyrimidine-3,7-dicarbonitrile (13c): Compound 13c was obtained as brown crystals (dioxane/ehanol), m.p. $290-292^{\circ} \mathrm{C}$; yield (64\%); IR (KBr): v $3390\left(\mathrm{NH}_{2}\right), 2205(\mathrm{CN}), 1640$ (CS) $\mathrm{cm}^{-1} ;{ }^{1} \mathrm{H}$ NMR: $\delta 1.35\left(s, 3 \mathrm{H}, \mathrm{CH}_{3}\right), 2.70(s$, $\left.3 \mathrm{H}, \mathrm{CH}_{3}\right), 303(s, 1 \mathrm{H}, \mathrm{CH}), 5.95(s, 1 \mathrm{H}$, olefinic- $\mathrm{H})$, $7 \cdot 10-7.66\left(m, 8 \mathrm{H}\right.$, aromatic-H and $\left.2 \mathrm{NH}_{2}\right) ; \mathrm{MS}: \mathrm{m} / \mathrm{z}$ (\%), 348 (29), 257 (35), 165 (100).

Anal. calcd. For $\mathrm{C}_{18} \mathrm{H}_{16} \mathrm{~N}_{6} \mathrm{~S}$ : C $62.1 ; \mathrm{H} 4.6 ; \mathrm{N}$ 24.1; S 9.2\%.

Found: C 62.0; H 4.9; N 24.4; S 9.0\%.

$2.3 \mathrm{~g}$ 2,8-diamino-4-(3,4,5-trimethoxyphenyl)-7-cyano-8-methyl-6-thioxo-7,8-dihydro-6H-pyrido[1,2-a] pyrimidine-3-carbothioamide (13d): Compound 13d was obtained as yellow crystals (ethanol/dioxane), m.p. $250-252^{\circ} \mathrm{C}$; yield $(66 \%)$; IR (KBr): $v 3450(b r$, $\left.\mathrm{NH}_{2}\right), 2205(\mathrm{CN}), 1650(\mathrm{CS}) \mathrm{cm}^{-1}$; ${ }^{1} \mathrm{H}$ NMR: $\delta 1.35$ 
$\left(s, 3 \mathrm{H}, \mathrm{CH}_{3}\right), 2 \cdot 15\left(b r, 2 \mathrm{H}, \mathrm{CSNH}_{2}\right), 2.90(s, 1 \mathrm{H}$, $\mathrm{CH}), 3.95\left(s, 9 \mathrm{H}, 3 \mathrm{OCH}_{3}\right), 5.80(s, 1 \mathrm{H}$, olefinic- $\mathrm{H})$, $7.00-7.79\left(m, 6 \mathrm{H}\right.$, aromatic-H and $\left.2 \mathrm{NH}_{2}\right) ; \mathrm{MS}: m / z$ (\%), 458 (19), 178 (43), 165 (100).

Anal. calcd. For $\mathrm{C}_{20} \mathrm{H}_{22} \mathrm{~N}_{6} \mathrm{~S}_{2} \mathrm{O}_{3}$ : C 52.4; $\mathrm{H} 4.8 ; \mathrm{N}$ $18 \cdot 3$; S 14.0\%.

Found: C 52.1; H 4.9; N 18.5; S 13.6\%.

2.3h 2,8-Diamino-4-(4-chlorophenyl)-7-cyano-8methyl-6-thioxo-7,8-dihydro-6Hpyrido [1,2-a] pyrimidine-3-carbothioamide (13e): Compound 13e was obtained as brown crystals (dioxane), mp 233$235^{\circ} \mathrm{C}$; yield $(62 \%)$; IR (KBr): $v 3445\left(b r, \mathrm{NH}_{2}\right)$, $2200(\mathrm{CN}), 1647$ (CS) $\mathrm{cm}^{-1}$; 1H NMR: $\delta 1.35(s$, $\left.3 \mathrm{H}, \mathrm{CH}_{3}\right), 2 \cdot 15,\left(b r, 2 \mathrm{H}, \mathrm{CSNH}_{2}\right), 2.95(s, 1 \mathrm{H}, \mathrm{CH})$, $5.90(s, 1 \mathrm{H}$, olefinic- $\mathrm{H}), 7 \cdot 10-7.75(\mathrm{~m}, 8 \mathrm{H}$, aromatic-H and $\left.2 \mathrm{NH}_{2}\right) ; \mathrm{MS}: m / z(\%), 402$ (26), 169 (100).

Anal. calcd. For $\mathrm{C}_{17} \mathrm{H}_{15} \mathrm{~N}_{6} \mathrm{~S}_{2} \mathrm{Cl}$ : C $50 \cdot 7 ; \mathrm{H} 3 \cdot 8 ; \mathrm{N}$ 20.9; S 15.9; $\mathrm{Cl} 8 \cdot 8 \%$.

Found: C 50.3; H 3.9; N 20.5; S 15.6; Cl 9.1\%.

$2.3 \mathrm{i} \quad 2,8-$ Diamino-4-(4-methylphenyl)-7-cyano-8-methyl-6-thioxo-7,8-dihydro-6H-pyrido[1,2-a]pyrimidine-3-carbothioamide (13f): Compound $13 \mathrm{f}$ was obtained as brown crystals (dioxane), mp 241$243^{\circ} \mathrm{C}$; yield $(72 \%)$; IR $(\mathrm{KBr}): v 3400\left(b r, \mathrm{NH}_{2}\right)$, $2225(\mathrm{CN}), 1645$ (CS) cm ${ }^{-1}$; ${ }^{1} \mathrm{H}$ NMR: $\delta 1.35(s, 3 \mathrm{H}$, $\left.\mathrm{CH}_{3}\right), 2.00,\left(\right.$ br s $\left., 2 \mathrm{H}, \mathrm{CSNH}_{2}\right), 2.35\left(s, 3 \mathrm{H}, \mathrm{CH}_{3}\right)$, $2.50\left(s, 3 \mathrm{H}, \mathrm{CH}_{3}\right), 2.99(s, 1 \mathrm{H}, \mathrm{CH}), 6 \cdot 10(s, 1 \mathrm{H}$, olefinic-H), 7.15-7.90 $\left(\mathrm{m}, 8 \mathrm{H}\right.$, aromatic- $\mathrm{H}$ and $\left.2 \mathrm{NH}_{2}\right)$; MS: $m / z$ (\%), 402 (26), 207 (37), 165(100).

Anal. calcd. For $\mathrm{C}_{18} \mathrm{H}_{18} \mathrm{~N}_{6} \mathrm{~S}_{2}$ : C $56.5 ; \mathrm{H} 4.7 ; \mathrm{N}$ $22 \cdot 0$; S $16 \cdot 8 \%$.

Found: C 56.2; H 4.3; N 21.6; S 16.6\%.

\subsection{General procedures for the preparation of} pyridotriazine derivatives $(\mathbf{1 6 a}, \boldsymbol{b})$

To a solution of either benzoylisothiocyanate or acetyl isothiocyanate $(0.01 \mathrm{~mol})$ [was prepared by refluxing eiher benzoylchloride or acetylchloride $(0.01 \mathrm{~mol})$ with ammonium thiocyanate $(0.76 \mathrm{~g}$, $0.01 \mathrm{~mol})$ in dry acetone] in dry acetone $(50 \mathrm{ml})$, tetrahydropyridinethione $4(1.8 \mathrm{~g}, 0.01 \mathrm{~mol})$ was added. The reaction mixture was refluxed for $2 \mathrm{hrs}$ and then poured onto water. The solid product, so formed was collected by filtration and crystallized from the proper solvent to give $\mathbf{1 6 a - b}$.

2.4a 8-Amino-8-methyl-4-phenyl-2,6-dithioxo-1,6, 7,8-tetrahydro-2H-pyrido[1,2-a] [1,3,5]triazine-7- carbonitrile (16a): Compound 16a was obtained as yellow crystals (dioxane), m.p. $271-273^{\circ} \mathrm{C}$; yield (62\%); IR (KBr): v $3370\left(\mathrm{NH}_{2}\right), 2195(\mathrm{CN}), 1635$ (CS) $\mathrm{cm}^{-1} ;{ }^{1} \mathrm{H}$ NMR: $\delta 1.00\left(s, 3 \mathrm{H}, \mathrm{CH}_{3}\right), 2.31(s$, $\left.3 \mathrm{H}, \mathrm{CH}_{3}\right), 2 \cdot 80(s, 1 \mathrm{H}, \mathrm{CH}), 5 \cdot 85(s, 1 \mathrm{H}$, olefinic- $\mathrm{H})$, $7.05\left(s, 2 \mathrm{H}, \mathrm{NH}_{2}\right), 10.50(s, 1 \mathrm{H}, \mathrm{NH}) ; \mathrm{MS}: m / z(\%)$, 265 (27), 165 (100).

Anal. calcd. For $\mathrm{C}_{15} \mathrm{H}_{13} \mathrm{~N}_{5} \mathrm{~S}_{2}$ : C $55.0 ; \mathrm{H} 4.0 ; \mathrm{N}$ 21.4; S 19.6\%.

Found: C $55 \cdot 4 ; \mathrm{H} 4 \cdot 3$; N 21.6; S 19.2\%.

$2.4 \mathrm{~b}$ 8-Amino-8-methyl-4-methyl-2,6-dithioxo-1,6, 7,8-tetrahydro--2H-pyrido[1,2-a] [1,3,5]triazine-7carbonitrile (16b): Compound 16b was obtained as yellow crystals (dioxane), m.p. $247-279^{\circ} \mathrm{C}$; yield (66\%); IR (KBr): v $3370\left(\mathrm{NH}_{2}\right), 2195(\mathrm{CN}), 1635$ (CS) $\mathrm{cm}^{-1} ;{ }^{1} \mathrm{H}$ NMR: $\delta 1.00\left(s, 3 \mathrm{H}, \mathrm{CH}_{3}\right), 2.31(s$, $\left.3 \mathrm{H}, \mathrm{CH}_{3}\right), 2 \cdot 80(s, 1 \mathrm{H}, \mathrm{CH}), 5 \cdot 85(s, 1 \mathrm{H}$, olefinic- $\mathrm{H})$, $7.05\left(s, 2 \mathrm{H}, \mathrm{NH}_{2}\right), 10 \cdot 50(s, 1 \mathrm{H}, \mathrm{NH}$; MS: $m / z(\%)$, 265 (27), 165 (100).

Anal. calcd. For $\mathrm{C}_{10} \mathrm{H}_{11} \mathrm{~N}_{5} \mathrm{~S}_{2}$ : C 45.3; H 4.2; N $26 \cdot 4$; S $24 \cdot 5 \%$.

Found: C 45.0; H 4.3; N 26.6; S 24.8\%.

\subsection{General procedures for the preparation of thiourea derivatives $(\mathbf{1 8 a}, \boldsymbol{b})$}

To a solution of arylisothiocyanate $\mathbf{1 7 a}$ or $\mathbf{1 7 b}$ $(0.01 \mathrm{~mol})$ in dry acetone $(20 \mathrm{ml})$ tetrahydro-pyridinethione $4(1.8 \mathrm{~g}, 0.01 \mathrm{~mol})$ was added. The reaction mixture was refluxed for $4 \mathrm{~h}$ then left to cool. The solid product, so formed was collected by filtration and crystallized from the proper solvent to give $(18 \mathrm{a}, \mathrm{b})$.

2.5a 1-(4-Amino-5-cyano-1,4,5,6-tetrahydro-4-methyl6-thioxopyridin-2-yl)-3-ptolylthiourea (18a): Compound 18a was obtained as brown crystals (dioxane), m.p. $217-219^{\circ} \mathrm{C}$; yield $(55 \%)$; IR (KBr): $v$ $3340\left(\mathrm{NH}_{2}\right), 3350(\mathrm{NH}), 2200(\mathrm{CN}), 1655(\mathrm{CS}) \mathrm{cm}^{-}$ 1. ${ }^{1} \mathrm{H}$ NMR: $\delta 2 \cdot 15\left(s, 3 \mathrm{H}, \mathrm{CH}_{3}\right), 2 \cdot 35\left(s, 3 \mathrm{H}, \mathrm{CH}_{3}\right)$, $2.90(s, 1 \mathrm{H}, \mathrm{CH}), 4.50(b r, 2 \mathrm{H}, 2 \mathrm{NH}), 5.90(s, 1 \mathrm{H}$, olefinic-H), 6.81-7.10 ( $m, 7 \mathrm{H}$, aromatic- $\mathrm{H}, \mathrm{NH}_{2}$ and NH); MS: $m / z$ (\%), 331 (27), 240 (52), 165 (100).

Anal. calcd. For $\mathrm{C}_{15} \mathrm{H}_{17} \mathrm{~N}_{5} \mathrm{~S}_{2}$ : C 54.4; H 5.2; N 21.1; S 19.4\%.

Found: C $54 \cdot 0 ; \mathrm{H} 5 \cdot 3 ; \mathrm{N} 21 \cdot 4 ; \mathrm{S}$ 19.8\%.

$2.5 \mathrm{~b}$ 1-(4-Amino-5-cyano-1,4,5,6-tetrahydro-4-methyl-6-thioxopyridin-2-yl)-phenylthiourea (18b): Compound 18b was obtained as brown crystals 
(dioxane), m.p. $210-212^{\circ} \mathrm{C}$; yield (59\%); IR ( $\mathrm{KBr}$ ): v $3340\left(\mathrm{NH}_{2}\right), 3350(\mathrm{NH}), 2200(\mathrm{CN}), 1655(\mathrm{CS})$ $\mathrm{cm}^{-1}$; ${ }^{1} \mathrm{H}$ NMR: $\delta 2 \cdot 10\left(s, 3 \mathrm{H}, \mathrm{CH}_{3}\right), 2 \cdot 85(s, 1 \mathrm{H}$, $\mathrm{CH}), 4.60(\mathrm{br}, 2 \mathrm{H}, 2 \mathrm{NH}), 6 \cdot 11(\mathrm{~s}, 1 \mathrm{H}$, olefinic-H), 6.81-7.15 $\left(m, 8 \mathrm{H}\right.$, aromatic- $\mathrm{H}, \mathrm{NH}_{2}$ and $\left.\mathrm{NH}\right)$; MS: $\mathrm{m} / \mathrm{z}$ (\%), 317 (27), 240 (52), 165 (100).

Anal. calcd. For $\mathrm{C}_{14} \mathrm{H}_{15} \mathrm{~N}_{5} \mathrm{~S}_{2}$ : C 53.0; H 4.7; N $22 \cdot 1 ; \mathrm{S} 20 \cdot 2 \%$.

Found: C 53.3; H 4.3; N 22.4; S 19.8\%.

\subsection{General procedures for the preparation of} dihydropyridine derivatives $(24 a-e)$

Procedure (A): To a solution of 2-aminocrotononitrile (1) $(0.82 \mathrm{~g}, 0.01 \mathrm{~mol})$ in ethanol $(20 \mathrm{ml}) \mathrm{a}$ catalytic amount of piperidine and arylidinemalononitrile 19a-c or arylidine cyanothioacetamide derivatives $19 \mathrm{~d}, \mathbf{e}(0.01 \mathrm{~mol})$ were added. The reaction mixture was refluxed for $4 \mathrm{~h}$ and then left to cool. The solid product, so formed was collected by filtration and crystallized from the proper solvent to give 24a-e.

Procedure (B): To a solution of 2-aminocrotononitrile (1) $(0.82 \mathrm{~g}, 0.01 \mathrm{~mol})$ in glacial acetic acid $(20 \mathrm{ml})$ the corresponding aldehyde $25 \mathrm{a}-\mathbf{e}(0.01 \mathrm{~mol})$ was added. The reaction mixture was refluxed for $4 \mathrm{~h}$ and then left to cool. The solid product, so formed was collected by filtration and crystallized from the proper solvent to give $\mathbf{2 4 a - e}$.

2.6a 4-(2-Chlorophenyl)-1,4-dihydro-2, 6-dimethylpyridine-3,5-dicarbonitrile (24a): Compound 24a was obtained as yellow crystals (dioxane), m.p. 262-264 ${ }^{\circ} \mathrm{C}$; yield (55\%); IR (KBr): v $3340(\mathrm{NH})$, $2210(\mathrm{CN}) \mathrm{cm}^{-1} ;{ }^{1} \mathrm{H}$ NMR: $\delta 2.08\left(s, 6 \mathrm{H}, 2 \mathrm{CH}_{3}\right)$, $4.60(\mathrm{~s}, 1 \mathrm{H}, 4 \mathrm{H}-$ pyridine $), 7 \cdot 32-8.11(\mathrm{~m}, 4 \mathrm{H}$, aromatic-H), $9.70(s, 1 \mathrm{H}, \mathrm{NH})$; MS: $m / z(\%), 269$ (27), 158 (100).

Anal. calcd. For $\mathrm{C}_{15} \mathrm{H}_{12} \mathrm{~N}_{3} \mathrm{Cl}$ : C $66.8 ; \mathrm{H} 4.9 ; \mathrm{N}$ $15 \cdot 9 ; \mathrm{Cl} 13 \cdot 1 \%$.

Found: C 66.6; H 4.6; N 15.7; Cl 13.3\%.

$2.6 \mathrm{~b}$ 1,4-Dihydro-4-(4-methoxyphenyl)-2,6-dimethylpyridine-3,5-dicarbonitrile (24b): Compound 24b was obtained as yellow crystals (dioxane), m.p. $223-225^{\circ} \mathrm{C}$; yield $(75 \%)$; the spectral data of this compound is compatible with the reported structure in literature. ${ }^{14}$

2.6c 4-(4-Bromophenyl)-1,4-dihydro-2,6-dimethylpyridine-3,5-dicarbonitrile (24c): Compound 24c was obtained as orange crystals (ethanol/dimethylforamide), m.p. $210-212^{\circ} \mathrm{C}$; yield (75\%); IR (KBr): v $3340(\mathrm{NH}), 2205(\mathrm{CN}) \mathrm{cm}^{-1}$; MS: $\mathrm{m} / z(\%), 314$ (33), 159 (100); ${ }^{1} \mathrm{H}$ NMR: $\delta 2 \cdot 00\left(s, 6 \mathrm{H}, 2 \mathrm{CH}_{3}\right), 4.60$ $(s, 1 \mathrm{H}, 4 \mathrm{H}-$ pyridine $), 7 \cdot 10-8 \cdot 10(m, 4 \mathrm{H}$, aromatic$\mathrm{H}), 9.53(s, 1 \mathrm{H}, \mathrm{NH})$.

Anal. calcd. For $\mathrm{C}_{15} \mathrm{H}_{12} \mathrm{~N}_{3} \mathrm{Br}$ : C 57.3; H 3.9; N $13 \cdot 8 ; \mathrm{Br} 25 \cdot 4 \%$.

Found: C 57.5; H 3.6; N 13.7; Br 25.2\%.

2.6d 1,4-Dihydro-2,6-dimethyl-4-(3-nitrophenyl)pyridine-3,5-dicarbonitrile (24d): Compound $24 \mathrm{~d}$ was obtained as brown crystals (ethanol/dimethylforamide, m.p. $225-227^{\circ} \mathrm{C}$; yield $(60 \%)$; IR $(\mathrm{KBr}): v$ $3340(\mathrm{NH}), 2215(\mathrm{CN}) \mathrm{cm}^{-1}$; ${ }^{1} \mathrm{H}$ NMR: $\delta 2.08(s$, $\left.6 \mathrm{H}, 2 \mathrm{CH}_{3}\right), 4 \cdot 70(\mathrm{~s}, 1 \mathrm{H}, 4 \mathrm{H}$-pyridine $), 7 \cdot 11-8 \cdot 20(\mathrm{~m}$, $4 \mathrm{H}$, aromatic-H), $9 \cdot 17(s, 1 \mathrm{H}, \mathrm{NH})$. MS: $m / z(\%)$, 280 (23), 158 (100).

Anal. calcd. For $\mathrm{C}_{15} \mathrm{H}_{12} \mathrm{~N}_{4} \mathrm{O}_{2}: \mathrm{C} 64 \cdot 3 ; \mathrm{H} 4 \cdot 3 ; \mathrm{N}$ $20.0 \%$.

Found: C 64.0; H 4.0; N 20.3\%.

2.6e 1,4-Dihydro-4-(2,3,4-trimethoxyphenyl)-2,6dimethylpyridine-3,5-dicarbonitrile (24e): Compound 24e was obtained as black crystals (dimethylforamide), m.p. $291-292^{\circ} \mathrm{C}$; yield (60\%); IR (KBr): $v 3340(\mathrm{NH}), 2220(\mathrm{CN}) \mathrm{cm}^{-1}$; ${ }^{1} \mathrm{H}$ NMR: $\delta 1.9(s$, $\left.6 \mathrm{H}, 2 \mathrm{CH}_{3}\right), 3.80\left(s, 9 \mathrm{H}, 3 \mathrm{OCH}_{3}\right), 7 \cdot 10-8.03(s, 2 \mathrm{H}$, aromatic-H), $9.7(s, 1 \mathrm{H}, \mathrm{NH}) . \mathrm{MS}: m / z(\%), 325$ (40), 159 (100).

Anal. calcd. For $\mathrm{C}_{18} \mathrm{H}_{19} \mathrm{~N}_{3} \mathrm{O}_{3}$ : C 66.5; H 5.9; N $12.9 \%$.

Found: C $66 \cdot 3$; H $5 \cdot 7$; N 12.7\%.

\section{Discussion}

In our previous work from our laboratories we have explored the synthetic potentiality of $\beta$-enaminonitriles $^{1-3}$ and enaminones. ${ }^{4,5}$ In continuation of our interest in developing the synthesis of polyfunctionally substituted heteroaromatics, we report here on the utility of 2-aminocrotononitrile (1) as a precursor for the synthesis of polyfunctionally substituted pyridines and pyridopyrimidines. Thus, it has been found that 1 reacted with cyanothioacetamide in refluxing dioxine to give tetrahydropyridinthione (4) in a quantitative yield. The structure of $\mathbf{4}$ was based on its spectral analysis. The formation of $\mathbf{4}$ from the reaction of 1 and cyanothioacetamide is believed to be via the initial addition of cyanothioacetamide to 1 to give the acyclic intermediate $\mathbf{2}$ that cyclize readily 


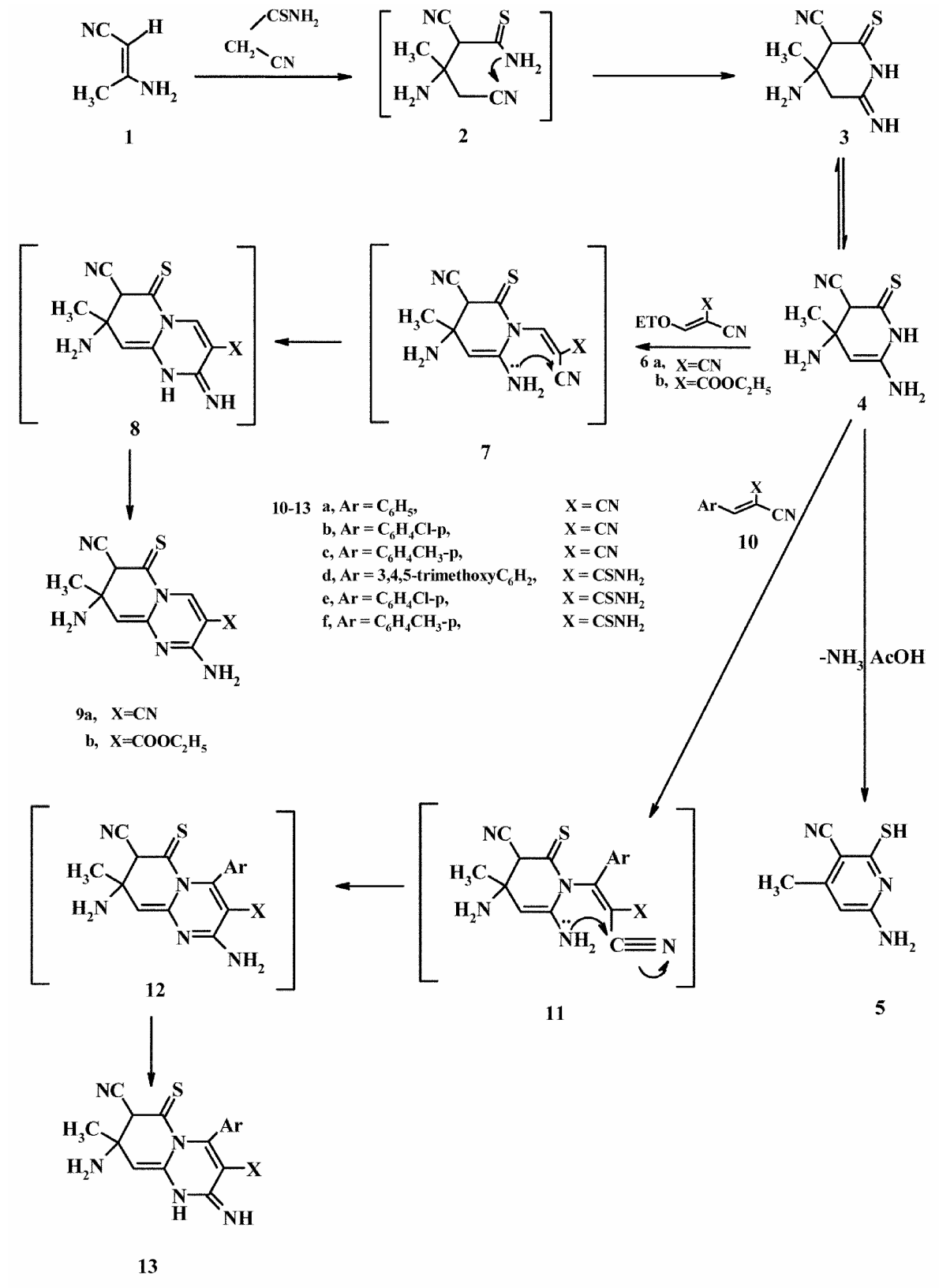

Scheme 1.

into 3 and tautomerizes into 4 (scheme 1). Heating of 4 in refluxing acetic acid for about $5 \mathrm{~h}$ resulted in the formation of pyridine derivative $\mathbf{5}$ via elimination of $\mathrm{NH}_{3}$. The structure of $\mathbf{5}$ was based on its spectral data and elemental analysis (scheme 1).

Compound 4 was reacted with ethoxymethylenemalononitrile (6a) in refluxing ethanol/piperidine to give pyridopyrimidinthione derivative 9a. Establishing of structure 9a was based on its spectral data and elemental analysis. Formation of 9a from 4 and ethoxymethylenemalononitrile (6a) was believed to be formed via Michael type addition of compound 4 on 6a followed by ethanol elimination to give the acyclic intermediate 7 which is then underwent intramolecular cyclization and subsequent tautomerism to give 9a as demonstrated in scheme 1 . Similarly, compound $\mathbf{4}$ reacted with $\mathbf{6 b}$ to give the corresponding pyridopyrimidinthione derivative $\mathbf{9 b}$ (scheme 1).

Furthermore, the behaviour of tetrahydropyridinthione (4) towards some electrophilic reagents such as arylidenemalononitrile and arylidenecyanothioacetamide was also investigated. Thus, compound $\mathbf{4}$ was reacted with benzylidenemalononitrile (10a) in refluxing ethanol and in the presence of piperidine to give the pyridopyrimidinethione derivative 13a 


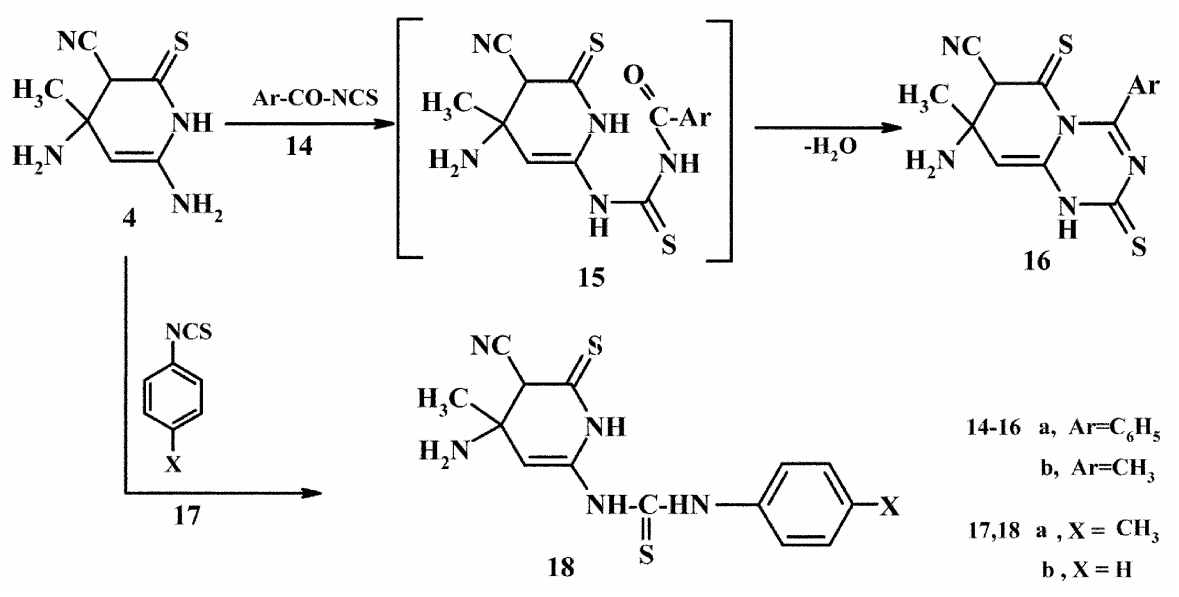

Scheme 2.

via intermediacy of Michael adduct 11a. Formation of compound 13a from the reaction of 4 and arylidene 10a is believed to be formed via initial Michael addition of compound 4 on arylidene 10a to give the acyclic non-isolable intermediate 11 a which underwent intramolecular cyclization and subsequent tautomerism to give 13a. Establishing of structure 13a was based on its spectral data. For example the ${ }^{1} \mathrm{H}$ NMR of compound 13a revealed the presence of a singlet signal at $\delta=1.35 \mathrm{ppm}$ corresponding to $\mathrm{CH}_{3}$, a singlet signal at $\delta=3 \cdot 10 \mathrm{ppm}$ corresponding to $s p^{3}$ proton, a singlet signal at $\delta=6.0 \mathrm{ppm}$ corresponding to $s p^{2}$ proton and a multiplet signal at $\delta=7 \cdot 15-7.91 \mathrm{ppm}$ corresponding to aromatic protons and amino function. The mass spectrum of the same compound is in accordance with the proposed structure. Thus, it showed a molecular ion peak at 334. Similarly, compound 4 was reacted with arylidenmalononitriles $\mathbf{1 0 b}, \mathbf{c}$ in the same reaction condition to give pyridopyrimidinethione derivatives $\mathbf{1 3 b}, \mathbf{c}$ respectively (scheme 1).

Typical to the behaviour of arylidenemalononitriles toward 4, arylidenecyanothioacetamide $\mathbf{1 0 d}-\mathbf{f}$ was reacted with 4 in refluxing ethanol and in the presence of catalytic amount of piperdine to give the pyridopyrimidinthione derivatives 13d-f (scheme 1). Establishing of structures $13 \mathbf{d}-\mathbf{f}$ was based on their spectral data. For example ${ }^{1} \mathrm{H}$ NMR of $\mathbf{1 3 d}$ revealed the presence of a singlet signal at $\delta=1.35 \mathrm{ppm}$ corresponding to methyl group, a broad signal at $\delta=2.15 \mathrm{ppm}$ corresponding to $\mathrm{CSNH}_{2}$, a singlet signal at $\delta=2.90 \mathrm{ppm}$ corresponding to $s p^{3}$ proton, a singlet signal at $\delta=3.95 \mathrm{ppm}$ corresponding to aliphatic three methoxy groups, a singlet signal at $\delta=5.80 \mathrm{ppm}$ corresponding to olefinic proton and a multiplet signal at $\delta=7 \cdot 00-7.79 \mathrm{ppm}$ corresponding to aromatic protons and $\mathrm{NH}_{2}$. The mass spectrum of the same compound further supports the proposed structure. Thus, it showed a molecular ion peak at 458 , it also showed a fragment at 178 .

The behaviour of $\mathbf{4}$ towards isothiocyanate reagents was also investigated to proceed typical to literature reports. Thus, benzoyl isothiocyanate (14a) was reacted with 4 in refluxing acetone to give the pyridotriazine derivatives 16a via intermediacy of 15. Similarly, acetylisothiocyanate $(\mathbf{1 4 b})$ reacted with 4 in refluxing acetone to give 16b (scheme 2). Compound 4 reacted also with 4-tolylisothiocyanate (17a) in refluxing acetone to give the acyclic thiourea derivative 18a whose structure was established based on its elemental and spectral data (scheme 2). Similarly, phenyl isothiocyanate $(\mathbf{1 7 b})$ reacted with 4 to give $\mathbf{1 8 b}$.

In a previous work from our laboratory ${ }^{1,2}$ we have shown that $\beta$-enaminonitriles react readily with aliphatic, aromatic heteroaromatic aldehydes and some ketones to give pyridine and dihydropyridine derivatives analogous to a very important calcium channel blockers i.e. nifadipine drug. ${ }^{6-13}$ In continuation of this work we investigated the behaviour of 3aminocrotononitrile (1) towards some electrophilic reagents such as arylidenemalononitriles and arylidinecyanothioacetamides. Thus, it has been found that 3-aminocrotononitrile (1) reacted with arylidenmalononitriles 19a-c and arylidinecyanothioacetamides 19d,e to give dihydropyridine derivatives $24 a-e$. Establishing structure $\mathbf{2 4}$ was based on its spectral data and authentic specimen prepared from the reaction of 1 with the corresponding aldehydes derivatives $25 a-e$. Formation of $24 a-e$ from the reaction of 1 


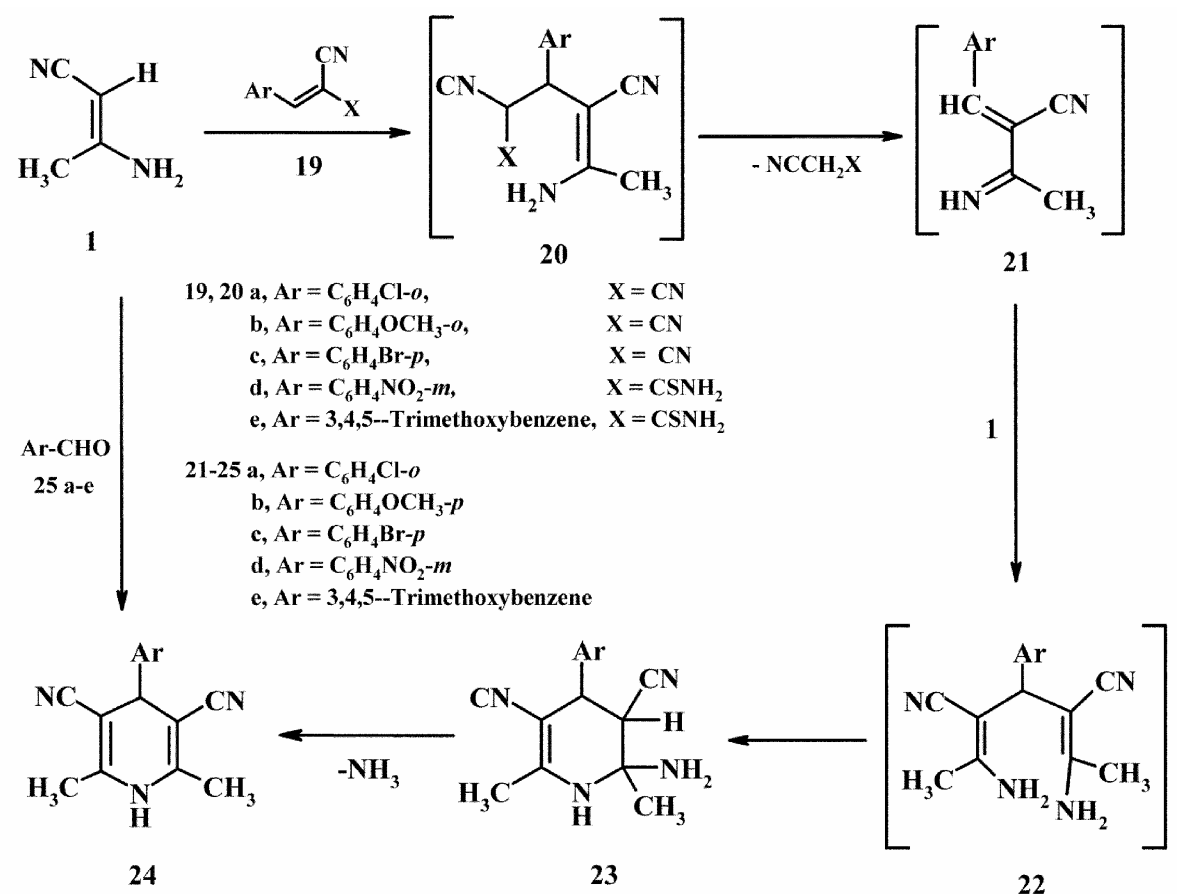

Scheme 3.

and arylidene derivatives $\mathbf{1 9} \mathbf{a}-\mathbf{e}$ is believed to be formed via initial addition of 1 on the double bond of arylidene to give the Michael adduct 20 that loses either malononitrile or cyanothioacetamide to give 21, which reacts further with one mole of 1 to give the acyclic intermediate 22 that gives the dihydropyridine 24 via cyclization and subsequent loss of NH3 (scheme 3).

\section{Conclusion}

The synthesis of a number of new tetrahydropyridinethiones, pyridopyrimidines, pyridotriazines and dihydropyridines was achieved by utilizing the chemistry of $\beta$-enaminonitriles.

\section{References}

1. Hafiz I S A 2000 Z. Naturforsch. B55 321

2. Hafiz I S A, Darwish E S and Mahmoud F F $1999 \mathrm{~J}$. Chem. Res. 3254

3. El Ghandour A H H, Ibrahim M K A, Hafiz I S A and Elnagdi M H 1991 Z. Naturforsch
4. Hassanien A Z A, Ghozlan S A S and Elnagdi M H 2003 J. Heterocyclic Chem. 40225

5. Abdel-Khalik M M and Elnagdi MH 2002 Synth. Comm. 32159

6. Hemmateenejad B, Miri R, Tabarzad M, Jafarpour M and Zand F $2004 \mathrm{~J}$. Mol. Struct. (THEOCHEM) $\mathbf{6 8 4}$ 43

7. Sathya Subramani, Caroline Vijayanand and Elizabeth Tharion 2002 British J. Pharmacol. 137756

8. Friedrich Bossert, Horst Meyer and Egbert Wehinger Angewandte Chemie International Edition in English 2003 Volume 20, Issue 9, pp. 762-769

9. Bohlooli S, Mahmoudian M, Skellern G G, Grant M H and Tettey J N A 2004 J. Pharm. Pharmacol. 2004561469

10. Miri R, Javidnia $K$, Kebriaie-Zadeh A, Niknahad H, Shaygani N, Semnanian S and Shafiee A Arch. Pharm. Pharm. Med. Chem. 336422

11. Miri R, Javidnia K, Hemmateenejad B, Azarpira A and Amirghofran Z 2004 Bioorg. Med. Chem. 12 2529

12. Navidpour L, Shafaroodi H, Miri R, Dehpour A R and Shafiee I L 2004 FARMACO 59261

13. Akhond B, Miri M and Shamsipur R M 2003 J Chem. Inf. Comput. Sci. $\mathbf{4 3} 1328$

14. Belén Batanero, Fructuoso Barba and Avelino Martín 2002 J. Org. Chem. 672369 